\title{
Is Aboriginal† nutrition a priority for local government? A policy analysis
}

\author{
Catherine Helson ${ }^{1}$, Ruth Walker ${ }^{1}$, Claire Palermo ${ }^{1, *}$, Kim Rounsefell $^{1}$, Yudit Aron ${ }^{1}$, \\ Catherine MacDonald ${ }^{2}$, Petah Atkinson ${ }^{2}$ and Jennifer Browne ${ }^{2}$ \\ 'Department of Nutrition and Dietetics, Monash University, Level 1, 264 Ferntree Gully Road, Notting Hill, VIC \\ 3168, Australia: ${ }^{2}$ Victorian Aboriginal Community Controlled Health Organisation, Collingwood, Victoria, Australia
}

Submitted 20 October 2016: Final revision received 23 May 2017: Accepted 22 June 2017: First published online 14 August 2017

\begin{abstract}
Objective: The present study aimed to explore how Australian local governments prioritise the health and well-being of Aboriginal populations and the extent to which nutrition is addressed by local government health policy.

Design: In the state of Victoria, Australia, all seventy-nine local governments' public health policy documents were retrieved. Inclusion of Aboriginal health and nutrition in policy documents was analysed using quantitative content analysis. Representation of Aboriginal nutrition 'problems' and 'solutions' was examined using qualitative framing analysis. The socio-ecological framework was used to classify the types of Aboriginal nutrition issues and strategies within policy documents.

Setting: Victoria, Australia.

Subjects: Local governments' public health policy documents $(n 79)$.

Results: A small proportion (14\%, $n$ 11) of local governments addressed Aboriginal health and well-being in terms of nutrition. Where strategies aimed at nutrition existed, they mostly focused on individual factors rather than the broader macroenvironment.

Conclusions: A limited number of Victorian local governments address nutrition as a health issue for their Aboriginal populations in policy documents. Nutrition needs to be addressed as a community and social responsibility rather than merely an individual 'behaviour'. Partnerships are required to ensure Aboriginal people lead government policy development.
\end{abstract}

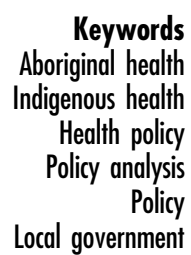

Australia's Indigenous population, the Aboriginal and Torres Strait Islander peoples, represent the world's oldest continuous culture, yet continue to experience significant health disparities compared with non-Indigenous Australians ${ }^{(1-3)}$. This is despite collective agreement by all Australian governments to improve health outcomes for Aboriginal and Torres Strait Islander peoples ${ }^{(4)}$. Aboriginal and Torres Strait Islander peoples have a life expectancy that is approximately 10 years lower than that of nonIndigenous Australians ${ }^{(5)}$. Preventable chronic conditions, such as CVD and type 2 diabetes, are among the leading causes of poor health and premature death ${ }^{(1,6)}$. Historical factors such as colonisation, dispossession of land and discriminatory government policies and practices as well as ongoing socio-economic inequality contribute to the poor health of Aboriginal and Torres Strait Islander

$\dagger$ In this paper, the term 'Aboriginal' is used to refer to Aboriginal and Torres Strait Islander peoples living in Victoria and Australia. peoples. Health and well-being are influenced by multiple factors such as the social, economic and environmental conditions in which people live. The socio-ecological model of health is a holistic approach that considers these factors $^{(7)}$. It takes account of the macroenvironment including culture, society and politics, the microenvironment including community cohesion and access to services, and how these interrelate with individual choices. The conventional social determinants of health, such as employment, education and access to health-care services, interact with Indigenous-specific determinants, such as racism and (dis)connection to land, family and culture, and continue to impact health outcomes ${ }^{(8)}$.

It is well documented that nutrition plays a crucial role in the prevention of non-communicable diseases ${ }^{(9)}$. Dietary factors and excess weight are among the leading contributors to burden of disease in the Aboriginal and Torres Strait Islander population. These are each responsible for about $15 \%$ of the gap in health outcomes ${ }^{(10)}$. 
Aboriginal and Torres Strait Islander peoples are less likely to meet the national guidelines for fruit and vegetable intake and consume more energy-dense 'discretionary foods' than other Australians ${ }^{(2,3)}$. In addition, Aboriginal and Torres Strait Islander households are six times more likely to experience food insecurity than other Australian households ${ }^{(11)}$, suggesting that this population faces physical, social and financial barriers to accessing adequate and nutritious food on a consistent basis.

Local governments (also known as 'local authorities' or 'councils') play a crucial role in improving the health and well-being of communities. Local government is the unit of government closest to the community and thus best positioned to address factors that influence the health of the community ${ }^{(12)}$. Public health policies implemented through local government can support health-promoting environments within the municipality and reduce barriers to accessing health services, particularly for those who experience inequities, such as Aboriginal and Torres Strait Islander populations ${ }^{(13-16)}$. While it is well documented that improving nutrition is a key factor required for promoting health equity for Aboriginal peoples ${ }^{(17)}$, there is currently little understanding of how these issues have been considered by local governments. The aim of the present study was to determine how local governments prioritise the health and well-being of their Aboriginal populations within health policy documents and the extent to which nutrition issues are addressed.

\section{Methods}

\section{Setting}

The present study was conducted in Victoria, Australia. Of Victoria's 6 million people, just under 50000 (0.9\%) identify as Aboriginal and/or Torres Strait Islander ${ }^{(18)}$. Victoria has seventy-nine local governments: thirty-one in metropolitan Melbourne and forty-eight regional cities and rural shires. The Aboriginal population within local government areas varies from $0 \cdot 2$ to $5 \cdot 2 \%$ and twelve local government areas have greater than 1000 Aboriginal residents ${ }^{(19)}$. In Victoria, local governments are required to develop a Municipal Public Health and Wellbeing Plan (MPHWP) that serves as a mechanism to promote health and prevent illness. The MPHWP is a companion document to the overall strategic Council Plan ${ }^{(20)}$. As such, these two policies represent the views, priorities and values of local governments. In the field of Aboriginal and Torres Strait Islander health, some municipalities also have Aboriginal Community Controlled Health Organisations (ACCHO). These ACCHO are "primary health care services initiated and operated by the local Aboriginal community to deliver holistic, comprehensive, and culturally appropriate health care to the community which controls it, through a locally elected Board of Management ${ }^{\text {(21) }}$. ACCHO are funded predominantly by the Commonwealth
Department of Health and it is unknown what, if any, strategic relationships exist between ACCHO and local governments.

\section{Theoretical framework}

The present research employed an interpretive policy analysis approach informed by the socio-ecological model of health $^{(22)}$ and framing theory ${ }^{(23)}$. Previous research had identified that policy process theories have been underutilised in public health nutrition policy research ${ }^{(24,25)}$. The political science literature suggests that policy agenda setting is determined by the articulation of 'problems', matching these with policy 'solutions' and the broader social and political environment ${ }^{(26)}$. Furthermore, the way in which public health nutrition issues are framed is a key driver of policy action ${ }^{(27)}$. Thus, an interrogation of how issues are 'framed' and situated within the macroenvironment provides valuable insight into how language is used to shape the content of local government policy. Framing is an interpretive, sociological concept ${ }^{(28)}$ which is concerned with the way in which meaning is constructed. Frame analysis originated from the work of Goffman ${ }^{(29)}$ and is often used to examine public policy in order to determine how policy actors perceive issues (the 'problems') and propose to address them through policy 'solutions' ${ }^{,(30,31)}$. Schön ${ }^{(30)}$ contends that the same issue can be framed in a number of ways and this framing will determine which policy solutions are proposed to address the issue. Framing theory has previously been applied in the analysis of Aboriginal health policy processes in order to examine the ways in which policy stakeholders mobilise support for their agenda ${ }^{(32)}$.

The socio-ecological model of health considers the relationship between people and the systems in which they live ${ }^{(22)}$. The model conceptualises public health policies and interventions as sitting within one of five domains. The Individual domain includes factors specific to the individual such as socio-economic disadvantage, behaviours, knowledge, skills and self-perceptions. The Interpersonal domain comprises primary social relations such as friends, family and co-workers. The Organisational domain targets workplaces and institutions such as schools, hospitals and public services. The Community domain involves communitylevel characteristics such as socio-economic status, the physical environment, community values and beliefs. Finally, the Policy domain includes local, state and federal government policies ${ }^{(33)}$. This model is a useful theoretical framework for analysing Aboriginal health policy as it is consistent with the holistic conceptualisation of Aboriginal health, which is viewed as 'not just the physical well-being of an individual but refers to the social, emotional and cultural well-being of the whole Community ${ }^{\text {(34) }}$. The social-ecological model has been used in other areas of Aboriginal health research including as a framework for analysing the physical activity of Aboriginal Australians and in the evaluation of health promotion activities ${ }^{(35,36)}$. 
Previous research using framing analysis to examine representations of obesity among the Aboriginal population identified that the causes of and solutions for obesity were often framed in terms of biological, individual/ behavioural or social/structural determinants ${ }^{(37)}$. Thus we propose that the combination of framing theory and the social-ecological model of health provides a useful framework for analysing the representation of Aboriginal nutrition issues. Framing theory guided the coding of policy documents and the socio-ecological model was used to map the inductively identified frames into a conceptual framework. In combining these two theoretical approaches, we seek to understand how Victorian local governments conceptualise and address Aboriginal nutrition issues.

\section{Data collection}

The sample comprised the Municipal Public Health and Wellbeing policy documents from all seventy-nine Victorian local governments. A single copy of each policy document was sourced from each local government website on 31 March 2015. Documents not available online were sourced directly from local governments via telephone and email requests. Policy documents were included in analysis if they were current (i.e. for the period 2013-2017 inclusive) and published in a format that would allow for keyword searching using Adobe Acrobat Reader 2015 (Adobe Systems Incorporated, San Jose, CA, USA). A number of local governments did not publish a standalone MPHWP. Instead these were incorporated into their Council Plans. In these cases, the entire Council Plan document was included for analysis. Additionally, some local governments produced MPHWP Action Plans as appendices to the main document and these were also included for analysis. Characteristics of the local governments were recorded. These included types of policy document (MPHWP/Council Plan), location (metropolitan/ regional) and whether there was an ACCHO located in the municipality.

\section{Data analysis}

The iterative process of policy analysis involved two-steps: (i) content analysis; and (ii) framing analysis informed by Bowen $^{(38)}$. Content analysis involved analysis of 'Aboriginal' and 'nutrition' keyword frequencies within the documents and categorisation of content into where it was positioned within the document to clarify meaning and impact. The framing analysis involved examination of the text surrounding each keyword, followed by inductive coding for how nutrition was represented as a policy 'problem' and subsequently addressed in the policies.

\section{Content analysis}

Computer-assisted searches of the body of each policy document were performed to identify occurrences of keywords related to 'Aboriginal' (Aboriginal, Indigenous,
Koori) and 'nutrition' (nutrition, diet, weight, obesity, food, feeding, eating, feed). The frequencies of keywords in each policy document were recorded in Microsoft ${ }^{\circledR}$ Excel 2013 (Microsoft, Redmond, WA, USA) to provide a crude overview of the content of the policies.

Documents that did not use any Aboriginal keywords were excluded from further examination. Documents that included Aboriginal keywords were further examined to assess whether the Aboriginal keywords were in the context of nutrition.

A specifically designed data extraction spreadsheet, developed in Microsoft Excel 2013, was used to record the content analysis and to categorise the keywords and surrounding text according to their position within the document. Categories included: Background (Introduction/Policy Context); Goal (Priority Area); Objective; Strategy (Action/Intervention). Policy documents were initially read to determine the inclusion of Aboriginal health- and well-being-related content generally, as well as how they specifically addressed nutrition for Aboriginal Victorians. The text surrounding each identified keyword was then examined to identify the positioning of the keyword in the document in order to clarify the context, meaning and likely outcomes of what was stated in the documents. For example, some keywords appeared in background information only and did not appear in any priorities, objectives or strategies that addressed the issue. We also used the spreadsheet to extract information about policy development processes, including consultation with the Aboriginal community, and partnerships with Aboriginal organisations or communities.

Descriptive statistics were used to determine the median number of occurrences of each keyword per policy document and per context category (e.g. Background, Goal, Strategy). Frequency tables were used to analyse frequencies of all keywords and for all counts of context categories. The frequency of keywords identified within policy documents was compared according to the characteristics of the local governments, including location (metropolitan/regional) and presence of an ACCHO. The Mann-Whitney $U$ test was used to determine whether there was a significant difference in the median frequency of keywords between the independent groups above. Significance was set at $P<0 \cdot 05$. All statistical analyses were performed using the statistical software package IBM SPSS Statistics for Mac version 23.

\section{Framing analysis}

The qualitative analysis examined how nutrition issues among Aboriginal Victorians were framed in policy documents. This included how nutrition was represented as a policy 'problem' and subsequently addressed in the policies. A coding framework was developed by inductively analysing the text in which both 'Aboriginal' and 'nutrition' keywords were found and this was used to identify common frames. Emerging frames were grouped 
into categories (called 'master frames' by the authors) based on the domains of the socio-ecological framework: Individual, Interpersonal, Organisational, Community and Policy ${ }^{(33)}$. Basic descriptive statistics were also performed on the framing data to calculate number of policy documents that contained each frame.

Framing analysis was conducted independently by four researchers (C.H., R.W., Y.A. and K.R.). As the analysis was undertaken, results of independent coding were discussed between the researchers and frames further refined to enhance rigour.

The researchers were independent of Aboriginal public health nutrition practice within local government and completed cultural safety training prior to the commencement of the research. The study was overseen by an Aboriginal researcher (P.A.) and the results of analysis were discussed with the researcher to ensure they were relevant to the Victorian Aboriginal population.

Ethics approval was not required as the study used publicly available documents for analysis and the work did not directly involve human participants.

\section{Results}

\section{Keyword frequencies}

All seventy-nine local government policy documents were located for analysis. Of the seventy-nine documents, sixtyseven were MPHWP and twelve were Council Plans. Ten policy documents had separate annual Action Plans as appendices. Of the seventy-nine documents, the median frequency per policy document for 'Aboriginal' keywords was 5 (interquartile range 2-13) and for 'nutrition' keywords was 30 (interquartile range 16-45). Eleven (14\%) documents did not contain 'Aboriginal' keywords and thus were excluded from further analysis. The remaining sixtyeight documents were examined to ascertain whether Aboriginal nutrition was specifically mentioned. Of these documents, eleven contained 'Aboriginal' keywords in the context of 'nutrition' keywords (nine from regional Victoria and two from metropolitan Melbourne).

The number of 'Aboriginal' and 'nutrition' keywords appearing in policy documents varied (Table 1). Local governments located in areas with an ACCHO used more 'Aboriginal' keywords in their policy documents compared with local governments that did not have this service (median (interquartile range): 10 (3-17) v. 4 (1-8); $z=-2 \cdot 382 ; P=0 \cdot 01)$. There was no significant difference in the median frequency of 'Aboriginal' and 'nutrition' keywords between metropolitan and regional local government policies. The most common 'nutrition' keyword was 'food' (Table 1).

\section{Context of keywords}

A total of sixty-eight local governments made reference to Aboriginal health and well-being in their policies.
Approximately one-third ( $n$ 25, 37\%) of these documents mentioned Aboriginal health and well-being only in background information, for example when describing demographics and health data, or recognised the Aboriginal community as being a 'vulnerable' or 'at-risk' population. These policies, however, did not contain any specific goals, objectives or strategies addressing Aboriginal health and well-being.

Just over half ( $n$ 38, 56\%) of the sixty-eight local governments referenced Aboriginal health and well-being in their policies with at least one goal, objective or strategy that addressed Aboriginal health and well-being. In total, there were 113 goals, objectives and strategies relevant to Aboriginal health and well-being, addressing issues and initiatives such as social inclusion, community connectedness, reconciliation, partnerships and cultural heritage. These were most commonly centred on social inclusion, community connectedness, reconciliation, partnerships and cultural heritage. Almost two-thirds ( $n$ 67) of the 113 goals, objectives and strategies that did address Aboriginal health and well-being were identified in documents from local governments that reported having partnerships with Aboriginal organisations.

Only eleven local governments referenced the nutrition of Aboriginal Victorians in policy documents (Table 2). Over one-third of these ( $n$ 4) mentioned Aboriginal nutrition issues in background information only. No further commitment was documented to improving nutrition in these four plans. Seven policy documents included priorities, objectives or strategies that specifically addressed the nutrition of Aboriginal Victorians.

\section{Framing analysis}

A variety of frames were identified in the eleven policy documents that included Aboriginal nutrition content. The nutrition issues of Aboriginal Victorians were represented in several ways, with causes of nutrition problems attributed to all levels of the socio-ecological model of health: individual, interpersonal, organisational, community and policy (Table 3). While framing of nutrition issues as an individual problem predominated, 'solutions' were occasionally framed at the community level.

\section{Individual level: Nutrition is an individual issue} In most policies, nutrition issues among Aboriginal Victorians were attributed to the individual. The most common individual-level frame was 'Poor Food Choices'. Less frequently represented frames included 'Risk of Chronic Conditions' and 'Overweight and Obesity'. These frames were usually in background information:

\footnotetext{
'Aboriginals in rural areas are less likely to eat fruit compared to non-Aboriginals.' (Regional LG 1, p. 44; frame: 'Poor Food Choices')
} 
Table 1 Median frequency of 'Aboriginal' and 'nutrition' keywords in Victorian local government public health policies

\begin{tabular}{|c|c|c|c|c|c|c|c|c|c|c|}
\hline \multirow[b]{3}{*}{ Keywords } & \multicolumn{5}{|c|}{ Local government region } & \multicolumn{5}{|c|}{$\mathrm{ACCHO}$ in local government area } \\
\hline & \multicolumn{2}{|c|}{ Metro $(n 31)$} & \multicolumn{2}{|c|}{ Regional ( $n$ 48) } & \multirow[b]{2}{*}{$P$ value } & \multicolumn{2}{|c|}{ Yes $(n$ 22) } & \multicolumn{2}{|c|}{ No $(n 57)$} & \multirow[b]{2}{*}{$P$ value } \\
\hline & Median & IQR & Median & IQR & & Median & IQR & Median & IQR & \\
\hline \multicolumn{11}{|c|}{ Aboriginal terms } \\
\hline Aboriginal & 2 & $1-5$ & 2 & $1-6$ & & 6 & $2-11$ & 1 & $0-4$ & \\
\hline Indigenous & 2 & $1-5$ & 1 & $0-4$ & & 2 & $0-4$ & 1 & $0-4$ & \\
\hline Koori & 0 & $0-0$ & 0 & $0-0$ & & 0 & $0-0$ & 0 & $0-0$ & \\
\hline Total & 5 & $2-12$ & 5 & $1-12$ & $0.516^{\star}$ & 10 & $3-17$ & 4 & $1-8$ & $0.017 \dagger$ \\
\hline \multicolumn{11}{|l|}{ Nutrition terms } \\
\hline Nutrition & 1 & $0-3$ & 1 & $0-2$ & & 1 & $0-2$ & 1 & $0-2$ & \\
\hline Diet & 1 & $0-2$ & 2 & $0-3$ & & 1 & $0-3$ & 1 & $0-3$ & \\
\hline Weight & 2 & $1-5$ & 4 & $1-8$ & & 4 & $1-6$ & 3 & $1-6$ & \\
\hline Obesity & 2 & $0-6$ & 3 & $1-4$ & & 3 & $1-5$ & 2 & $0-5$ & \\
\hline Food & 15 & $7-25$ & 13 & $6-22$ & & 11 & $6-22$ & 13 & $7-22$ & \\
\hline Eating & 4 & $2-9$ & 5 & $2-8$ & & 5 & $1-9$ & 4 & $2-9$ & \\
\hline Feed & 0 & $0-0$ & 0 & $0-0$ & & 0 & $0-0$ & 0 & $0-0$ & \\
\hline Feeding & 0 & $0-3$ & 0 & $0-1$ & & 0 & $0-1$ & 0 & $0-1$ & \\
\hline Total & 34 & $15-46$ & 27 & $19-43$ & $0.699^{*}$ & 33 & $21-51$ & 29 & $14-44$ & $0.694^{*}$ \\
\hline
\end{tabular}

$\mathrm{IQR}$, interquartile range; $\mathrm{ACCHO}$, Aboriginal Community Controlled Health Organisation.

*Mann-Whitney $U$ test used for inferential analysis of keyword totals. No significant difference identified (all $P$ values $>0.05$ ).

†Mann-Whitney $U$ test used for inferential analysis of keyword totals. Significant difference identified.

'There are higher rates of ... overweight and obesity in the Indigenous population compared to the state and non-Indigenous rates.' (Regional LG 6, p. 12; frame: 'Overweight and Obesity')

Interpersonal level: Nutrition can be addressed through interpersonal strategies

'Social Connection' was the only interpersonal frame related to Aboriginal nutrition, used in only one of the policy documents. This frame took a more positive, strengths-based approach. It referred to a community kitchen programme operating in a metropolitan area (Metro LG 2). It offered an opportunity to improve nutrition, health and well-being through social connection and traditional Aboriginal foods.

Organisational level: Nutrition is an organisational issue Acknowledgement of the need to support employed Aboriginal health workers and increase this workforce was the only frame that addressed Aboriginal nutrition at an organisational level. Aboriginal health workers were identified in the document as being required to deliver programmes for the wider Aboriginal community:

'Support Aboriginal Health Workers to deliver programs to the wider Aboriginal community.' (Regional LG 2, p. 10; frame: 'Need for Aboriginal Health Workers')

\section{Community level: Nutrition is a community issue}

The role of community-level factors in determining the nutritional status of Aboriginal Victorians was represented in five documents. The most common community-level frame was 'Food Insecurity', identified in over one-third $(n$ 4) of the policies:
'Food insecurity affects $11 \%$... with Aboriginal Victorians 4 times as likely to have experienced one occurrence of food insecurity in the past year.' (Regional LG 9, p. 41; frame: 'Food Insecurity')

Policy: Nutrition is a policy priority and Nutrition is not a policy priority

In all policy documents ( $n$ 11) that underwent framing analysis, it was implied that Aboriginal nutrition needed to be improved and was framed as 'Nutrition is a policy priority'. Over half the documents ( $n$ 6) were framed as 'Partnerships are Important' as they recognised that partnerships with the Aboriginal community are important by acknowledging Aboriginal organisations that work alongside councils to improve the nutrition status of Aboriginal Victorians.

In contrast, in almost half the documents ( $n$ 5), the nutrition status of Aboriginal Victorians was framed as 'Not a policy priority'. Poor nutrition of Aboriginal Victorians was acknowledged or described the background information only, without any objectives or strategies that addressed the problem (Table 3).

\section{Discussion}

The present study is the first known attempt to examine how Aboriginal health and well-being are prioritised in local government policy documents. Content analysis of policy documents revealed that many local governments highlighted Aboriginal health and well-being issues in policy documents; however, the degree to which these were prioritised varied. Many local governments may have identified the poor health outcomes of their Aboriginal 
Table 2 Context of 'Aboriginal' and 'nutrition' keywords appearing together in Victorian local government public health policies

\begin{tabular}{|c|c|c|c|c|c|}
\hline Document & Development & Partnerships & Background & Goal & Strategy \\
\hline Regional LG 1 & Process not outlined & Nil & $\begin{array}{l}\text { Aboriginal people in rural areas are more } \\
\text { likely to experience food insecurity, be } \\
\text { obese, less likely to eat fruit }\end{array}$ & Nil & Nil \\
\hline Regional LG 2 & $\begin{array}{l}\text { Process outlined } \\
\text { Aboriginal consultation }\end{array}$ & $\begin{array}{l}\text { Elders } \\
\text { Local ACCHO } \\
\text { Local Aboriginal Network } \\
\text { Aboriginal Partnership } \\
\text { Project }\end{array}$ & Nil & Nil & $\begin{array}{l}\text { 'Close the Gap' activities } \\
\text { Nutrition programmes to Aboriginal } \\
\text { communities } \\
\text { Support Aboriginal health workers to deliver } \\
\text { programmes to the wider Aboriginal } \\
\text { community }\end{array}$ \\
\hline Regional LG 3 & $\begin{array}{l}\text { Process outlined } \\
\text { Aboriginal consultation }\end{array}$ & Local ACCHO & $\begin{array}{l}\text { Aboriginal Victorians are more likely to be } \\
\text { overweight or obese, experience } \\
\text { higher } \\
\text { rates of diabetes }\end{array}$ & Nil & Nil \\
\hline Regional LG 4 & $\begin{array}{l}\text { Process outlined } \\
\text { Aboriginal consultation } \\
\text { not documented }\end{array}$ & Nil & Nil & $\begin{array}{l}\text { Support healthy eating } \\
\text { and food security }\end{array}$ & $\begin{array}{l}\text { Refers to VACCHO's Victorian Aboriginal } \\
\text { Nutrition } \\
\text { and Physical Activity Strategy }\end{array}$ \\
\hline Regional LG 5 & $\begin{array}{l}\text { Process outlined } \\
\text { Aboriginal consultation } \\
\text { not documented }\end{array}$ & Nil & $\begin{array}{l}\text { Aboriginal people recognised as 'at-risk' } \\
\text { for unhealthy eating }\end{array}$ & $\begin{array}{l}\text { Increasing healthy } \\
\text { eating }\end{array}$ & Nil \\
\hline Regional LG 6 & Process not outlined & $\begin{array}{l}\text { Aboriginal Health } \\
\text { Sub-Committee } \\
\text { Local ACCHO }\end{array}$ & $\begin{array}{l}\text { Aboriginal people are more likely to be } \\
\text { overweight or obese }\end{array}$ & Nil & Nil \\
\hline Regional LG 7 & $\begin{array}{l}\text { Process outlined } \\
\text { Aboriginal consultation } \\
\text { not documented }\end{array}$ & Local ACCHO & Nil & Eating well & Nil \\
\hline Regional LG 8 & $\begin{array}{l}\text { Process outlined } \\
\text { Aboriginal consultation } \\
\text { not documented }\end{array}$ & Nil & $\begin{array}{l}\text { Aboriginal people recognised as 'at-risk' } \\
\text { for unhealthy eating }\end{array}$ & $\begin{array}{l}\text { Increasing healthy } \\
\text { eating }\end{array}$ & Nil \\
\hline Regional LG 9 & $\begin{array}{l}\text { Process outlined } \\
\text { Aboriginal consultation } \\
\text { not documented }\end{array}$ & Nil & $\begin{array}{l}\text { Aboriginal people in rural areas are more } \\
\text { likely } \\
\text { to experience food insecurity, be } \\
\text { obese, less likely to eat fruit }\end{array}$ & Nil & Nil \\
\hline Metro LG 1 & $\begin{array}{l}\text { Process outlined } \\
\text { Aboriginal consultation }\end{array}$ & $\begin{array}{l}\text { Aboriginal Women's Group } \\
\text { Aboriginal Advisory } \\
\text { Committee }\end{array}$ & Nil & Nil & $\begin{array}{l}\text { Support and integrate food security and healthy } \\
\text { eating initiatives as part of existing community } \\
\text { groups/social support programmes with a } \\
\text { focus on Aboriginal people }\end{array}$ \\
\hline Metro LG 2 & $\begin{array}{l}\text { Process outlined } \\
\text { Aboriginal consultation }\end{array}$ & $\begin{array}{l}\text { Social programme } \\
\text { including cooking and } \\
\text { nutrition education }\end{array}$ & Nil & Nil & $\begin{array}{l}\text { Work in partnership with key stakeholders for } \\
\text { integrated health promotion and planning }\end{array}$ \\
\hline
\end{tabular}


Table 3 Frames identified in in Victorian local government public health policy documents

\begin{tabular}{|c|c|c|}
\hline $\begin{array}{l}\text { Socio-ecological model } \\
\text { (master frame) }\end{array}$ & Frame & Examples taken from policy \\
\hline \multirow[t]{5}{*}{$\begin{array}{l}\text { Individual } \\
\text { (Nutrition is an individual issue) }\end{array}$} & Poor Food Choices & $\begin{array}{l}\text { 'Aboriginal people are less likely to eat fruit compared to non-Aboriginal } \\
\text { people.' (Regional LG } 1, \text { p. 44) }\end{array}$ \\
\hline & $\begin{array}{l}\text { Risk of Chronic } \\
\text { Conditions }\end{array}$ & 'Rates of diabetes higher in Aboriginal people.' (Regional LG 3, p. 17) \\
\hline & $\begin{array}{l}\text { Lower Life } \\
\text { Expectancy }\end{array}$ & 'Participate in "Close the Gap" activities.' (Regional LG 2, p. 9) \\
\hline & $\begin{array}{l}\text { Nutrition Knowledge } \\
\text { Poor }\end{array}$ & 'Deliver nutritional programs to Aboriginal communities.' (Regional LG 2, p. 10) \\
\hline & $\begin{array}{l}\text { Overweight and } \\
\text { Obesity }\end{array}$ & $\begin{array}{l}\text { 'Aboriginal people are more likely to be overweight or obese compared to non- } \\
\text { Aboriginal people.' (Regional LG 1, p. 41) }\end{array}$ \\
\hline $\begin{array}{l}\text { Interpersonal } \\
\text { (Nutrition can be addressed } \\
\text { through interpersonal strategies) }\end{array}$ & Social Connection & $\begin{array}{l}\text { 'Social program including cooking and nutrition (Koori Kitchen).' } \\
\text { (Metro LG 2, p. 1) }\end{array}$ \\
\hline $\begin{array}{l}\text { Organisational } \\
\text { (Nutrition is an organisational } \\
\text { issue) }\end{array}$ & $\begin{array}{l}\text { Need for Aboriginal } \\
\text { Health Workforce }\end{array}$ & $\begin{array}{l}\text { 'Support Aboriginal health workers to deliver programs to the wider Aboriginal } \\
\text { community.' (Regional LG 2, p.10) }\end{array}$ \\
\hline \multirow[t]{3}{*}{$\begin{array}{l}\text { Community } \\
\text { (Nutrition is a community issue) }\end{array}$} & Food Insecurity & $\begin{array}{l}\text { 'Support and integrate food security and healthy eating initiatives.' } \\
\text { (Metro LG 1, p. 68) }\end{array}$ \\
\hline & Health Inequality & 'Participate in "Close the Gap" activities.' (Regional LG 2, p. 9) \\
\hline & Respect for Culture & $\begin{array}{l}\text { 'Integrate ... initiatives as part of existing community groups and social support } \\
\text { programs with a focus on Aboriginal people.' (Metro LG } 1, \text { p. 68) }\end{array}$ \\
\hline \multirow[t]{2}{*}{$\begin{array}{l}\text { Policy } \\
\text { (Nutrition is a policy priority) }\end{array}$} & $\begin{array}{l}\text { Health Needs to be } \\
\text { Improved }\end{array}$ & $\begin{array}{l}\text { 'Healthy Lifestyle Choices (Healthy food and clean air are essential to } \\
\text { wellbeing). Strategic focus: Aboriginal health.' (Metro LG 2, p. 7) }\end{array}$ \\
\hline & $\begin{array}{l}\text { Partnerships are } \\
\text { Important }\end{array}$ & $\begin{array}{l}\text { 'Work in partnership with key stakeholders for integrated health promotion and } \\
\text { planning.' (Metro LG } 2, \text { p. 7) }\end{array}$ \\
\hline (Nutrition is not a policy priority) & & $\begin{array}{l}\text { Data in background information but no further priorities, programmes that } \\
\text { address the issue ( } n 5 \text {; Regional LG } 1,5,6,8 \text { and } 9 \text { ) }\end{array}$ \\
\hline
\end{tabular}

LG, local government.

community, yet in many cases, this did not always lead to specific actions. Our findings are consistent with other work demonstrating that Aboriginal nutrition appears to be a low priority on Australian policy agendas ${ }^{(17)}$.

These findings suggest that Aboriginal nutrition is not a priority for some local governments. Instead the focus is more broadly on Aboriginal health and well-being, mainly in the areas of social inclusion, community connectedness, reconciliation, partnerships and cultural heritage. A relatively small proportion of policies acknowledged the nutrition issues faced by Aboriginal Victorians and, those that did, often did so in background information, without including any objectives or strategies for improving Aboriginal nutrition. This is despite there being a degree of focus on nutrition for the general population as demonstrated by the frequency of nutrition terms appearing in the policies. Evidence would suggest that nutrition strategies outlined for the wider population are unlikely to be appropriate or effective for Aboriginal communities ${ }^{(39)}$. In addition, Aboriginal nutrition was more commonly included in the policies of local governments located in rural and regional Victoria. This is consistent with national efforts in Aboriginal food and nutrition tending to focus on rural and remote Aboriginal people rather than those living in cities ${ }^{(40)}$.

Where Aboriginal-specific nutrition issues were included, they were framed as individual-level 'problems'. As a result, where strategies to address nutrition for Aboriginal people existed, there was a strong focus on individual factors such as improving nutrition knowledge. In contrast, broader frames, such as those located in the community and policy domains, were less strongly represented. Structural factors that may affect nutrition such as transport, infrastructure and access to affordable food were not linked specifically to nutrition but rather access to health services, work and social connections. The finding that Aboriginal nutrition is often framed as an individual issue is consistent with studies exploring the framing of nutrition issues in mainstream Australia ${ }^{(41,42)}$. This is concerning as it is well recognised that health inequity is socially and structurally determined ${ }^{(7)}$.

Addressing the social and cultural determinants of Aboriginal health, including food insecurity, is recognised as a policy priority in Australia ${ }^{(43)}$. Health service-based interventions have not always improved Aboriginal health and well-being ${ }^{(34)}$. The current research identified that Victorian local governments do recognise these unique determinants, such as relationships and connectedness to culture in policy; however, only in a minority of cases was a social and cultural frame applied to improving nutrition. While individual knowledge and skills is one determinant of nutritional status, there are increasing calls for population-level policy approaches which incorporate structural changes and community engagement to halt the rise in obesity and diet-related chronic disease in an equitable manner ${ }^{(44)}$. Given the history of damaging, paternalistic Aboriginal affairs policy in Australia, it is essential that policies and programmes are developed in partnership with local Aboriginal communities ${ }^{(45)}$. 
Local governments that had partnerships with Aboriginal communities appeared to address Aboriginal health and well-being more comprehensively in policies emphasising the value of partnerships in Aboriginal health policy development. These partnerships may have had a greater influence on prioritisation of Aboriginal health and well-being in policy compared with those local governments that merely documented Aboriginal consultation in the development process. This finding is promising, as in the past, Aboriginal affairs policies have been characterised by a lack of meaningful consultation with Aboriginal people and an over-reliance on short-term solutions $^{(8,46)}$.

While there is evidence to suggest that local government policy can be an effective means for addressing nutrition in the general population ${ }^{(47,48)}$, our research indicates that progress by Victorian local governments to address Aboriginal nutrition is limited. The magnitude of what MPHWP are expected to achieve may be a reason for this. The health of the entire population in a local government area must be addressed in these documents, especially 'at-risk' populations ${ }^{(16)}$. This includes not only Aboriginal people but also other population subgroups such as culturally and linguistically diverse communities, children, the elderly and the homeless. Our study provides evidence of slow progress in addressing Aboriginal nutrition at the local government level.

\section{Future direction for local government policy}

Local governments can, and should, play an active role in Aboriginal health. Some are already doing this and these successful models of community engagement and policy development should be evaluated and disseminated to local governments in other areas.

Victorian local governments have demonstrated that significant gains in improving nutrition are possible through the development of population-level initiatives. One example is the Food for All programme that aimed to reduce food insecurity for disadvantaged communities by improving access to nutritious food with projects that were implemented in nine local government areas ${ }^{(49)}$. The evaluation outcomes and learning from this programme could inform future local government policy addressing food insecurity specifically for their Aboriginal populations. Additionally, community food programmes for Aboriginal people in Victoria have been acknowledged as a promising approach to reducing food insecurity and could be an effective initiative that local governments consider in the future ${ }^{(50)}$.

\section{Limitations}

A limitation of the present study is that local government policy was examined only in terms of what appeared in their public health plans. It is well recognised that policy is a broader process than the words written in the policy documents ${ }^{(51)}$. An examination of the Aboriginal health and nutrition strategies that have actually been implemented by local governments, incorporating Aboriginal views on these activities, is an important area for future research.

Local government may address Aboriginal health and well-being through a number of different mechanisms, such as other related plans and policies or through initiatives not formalised by policy. Therefore, findings of the study may not reflect local government's full commitment to Aboriginal health and nutrition. The content of other plans and policy documents that may contain Aboriginalspecific strategies, such as Aboriginal Actions Plans and Reconciliation Plans, should be investigated further.

Since the current review was undertaken, the Victorian Government's Healthy Together Victoria initiative, which provided significant funding to a number of local governments for public health nutrition, has ceased ${ }^{(52)}$. In addition, several local governments have been funded by the Victorian Department of Health and human Services to employ Aboriginal health promotion recruits ${ }^{(53)}$. Further research is required to determine whether these policy changes at the state government level impacted the prioritisation of nutrition (in general and for Aboriginal communities) at the local government level.

\section{Conclusions}

While many local governments consider improving the health and well-being of Aboriginal Victorians to be a priority, specific strategies for doing this are often not articulated in health policy documents. Only a small proportion (14\%) of Victorian local governments addressed Aboriginal nutrition. Where strategies to address Aboriginal nutrition existed, they mostly focused on individual factors rather than the macroenvironment.

In line with the social determinants of health literature, we recommend that local governments reframe nutrition as a community and social responsibility rather than merely an individual 'behaviour'. Nutrition strategies should consider the broader macroenvironment and incorporate fundamental aspects of Aboriginal health and well-being such as celebration of culture. Most importantly, these polices must be developed and implemented in partnership with Aboriginal organisations and communities.

\section{Acknowledgements}

Financial support: This research received no specific grant from any funding agency in the public, commercial or notfor-profit sector. Conflict of interest: None. Authorship: J.B. conceptualized the study with input from P.A., C.P. and C.M. C.H., R.W., K.R. and Y.A. collected and analysed the data. C.H. and R.W. drafted the manuscript. C.P. and J.B. revised the manuscript and sought feedback from all 
authors, who approved the final version of the manuscript. Ethics of human subject participation: Ethics approval was not required as the study used publicly available documents for analysis and the work did not directly involve human participants.

\section{References}

1. Australian Bureau of Statistics (2015) Leading Causes of Aboriginal and Torres Strait Islander Deaths. http://www.abs.gov.au/ ausstats/abs@.nsf/Lookup/by\%20Subject/3303.0 2012 Main\% 20Features Leading\%20Causes\%20of\%20Aboriginal\%20and $\%$ 20Torres\%20Strait\%20Islander\%20Deaths 10015 (accessed March 2015).

2. Australian Bureau of Statistics (2015) Australian Aboriginal and Torres Strait Islander Health Survey: Updated Results, 2012-13. http://www.abs.gov.au/ausstats/abs@.nsf/Lookup/ 4727.0.55.006main+features12012-13 (accessed June 2015).

3. Australian Bureau of Statistics (2015) Australian Aboriginal and Torres Strait Islander Health Survey: Nutrition Results Food and Nutrients, 2012-13. http://www.abs.gov.au/ ausstats/abs@.nsf/Lookup/by\%20Subject/4727.0.55.005 201213 Main\%20Features Discretionary\%20foods 16 (accessed June 2015).

4. Council of Australian Governments (2008) National Partnership Agreement on Closing the Gap on Indigenous Health Outcomes. http://www.federalfinancialrelations. gov.au/content/npa/health/_archive/ctg-health-outcomes/ national_partnership.pdf (accessed April 2017).

5. Australian Bureau of Statistics (2015) Life expectancy. http:// www.abs.gov.au/AUSSTATS/abs@.nsf/lookup/4704.0Chapter 218Oct+2010 (accessed April 2015).

6. Australian Bureau of Statistics (2015) Main causes of death. http://www.abs.gov.au/ausstats/abs@.nsf/Lookup/by\%20 Subject/3303.0 2012 Main\%20Features Deaths\%20of\%20 Aboriginal\%20and\%20Torres\%20Strait\%20Islander\%20Persons 10005 (accessed April 2015).

7. Wilkinson R \& Marmot M (editors) (2003) Social Determinants of Health: The Solid Facts. Geneva: WHO.

8. Carson B, Dunbar T, Chenhall R et al. (2007) Social Determinants of Indigenous Health. Crows Nest, NSW: Allen \& Unwin.

9. World Health Organization (2003) Diet, Nutrition and the Prevention of Chronic Diseases. Joint WHO/FAO Expert Consultation. WHO Technical Report Series no. 916. Geneva: WHO.

10. Australian Institute of Health and Welfare (2016) Australian Burden of Disease Study: Impact a Causes of Illness and Death in Aboriginal and Torres Strait Islander People 2011. Australian Burden of Disease Study Series no. 6. Catalogue no. BOD 7. Canberra, ACT: AIHW.

11. Australian Bureau of Statistics (2015) Australian Aboriginal and Torres Strait Islander Health Survey: Nutrition Results Food and Nutrients 2012-2013. Key findings. http://www. abs.gov.au/ausstats/abs@.nsf/mf/4727.0.55.005 (accessed March 2015).

12. Browne G, Davern M \& Giles-Corti B (2016) An analysis of local government health policy against state priorities and a social determinants framework. Aust N Z J Public Health 40, 126-131.

13. Victorian Government (2011) Victorian Public Health and Wellbeing Plan 2011-2015. Melbourne, VIC: Prevention and Population Health Branch, Department of Health.

14. Victorian Government (2012) Koolin Balit: Victorian Government Strategic Directions for Aboriginal Health 2012-2022. Melbourne, VIC: Victorian Government.

15. World Health Organization (2009) Milestones in Health Promotion Statement for Global Conferences. Geneva: WHO.
16. Victorian Government (2008) Public Health and Wellbeing Act 2008. http://www.austlii.edu.au/au/legis/vic/consol_act/ phawa2008222/ (accessed April 2015).

17. Browne J, Hayes R \& Gleeson D (2014) Aboriginal health policy: is nutrition the 'gap' in 'closing the gap'? Aust $N Z J$ Public Health 38, 362-369.

18. Australian Bureau of Statistics (2013) Estimates of Aboriginal and Torres Strait Islander Australians, June 2011. http://www.abs.gov.au/ausstats/abs@.nsf/mf/3238.0.55.001 (accessed January 2016).

19. Department of Health \& Human Services (2014) 2013 LGA Profiles Data. Melbourne, VIC: State Government of Victoria.

20. Department of Health \& Human Services (2017) Municipal public health and wellbeing planning. https://www2.health. vic.gov.au/public-health/population-health-systems/municipalpublic-health-and-wellbeing-planning (accessed August 2017).

21. National Aboriginal Community Controlled Health Organisation (2016) Homepage. http://www.naccho.org.au/ (accessed July 2016).

22. Johnston L, Doyle J, Morgan B et al. (2013) A review of programs that targeted environmental determinants of Aboriginal and Torres Strait Islander health. Int J Environ Res Public Health 10, 3518-3542.

23. van Hulst M \& Yanow D (2016) From policy 'frames' to 'framing': theorizing a more dynamic, political approach. Am Rev Public Admin 46, 92-112.

24. Clarke B, Swinburn B \& Sacks G (2016) The application of theories of the policy process to obesity prevention: a systematic review and meta-synthesis. BMC Public Health 16, 1084 .

25. Cullerton K, Donnet T, Lee A et al. (2016) Using political science to progress public health nutrition: a systematic review. Public Health Nutr 19, 2070-2078.

26. Kingdon J (2011) Agendas. Alternatives, and Public Policies. Boston, MA: Longman.

27. Cullerton K, Donnet T, Lee A et al. (2016) Playing the policy game: a review of the barriers to and enablers of nutrition policy change. Public Health Nutr 19, 2643-2653.

28. Garvin T \& Eyles J (2001) Public health responses for skin cancer prevention: the policy framing of Sun Safety in Australia, Canada and England. Soc Sci Med 53, 1175-1189.

29. Goffman E (1974) Frame Analysis: An Essay on the Organization of Experience. Cambridge, MA: Harvard University Press.

30. Schön DA (1987) Educating the Reflective Practitioner: Toward a New Design for Teaching and Learning in the Professions. San Francisco, CA: Jossey-Bass.

31. Schön DA (1983) The Reflective Practitioner: How Professionals Think in Action. New York: Basic Books.

32. Browne J, de Leeuw E, Gleeson D et al. (2017) A network approach to policy framing: a case study of the National Aboriginal and Torres Strait Islander Health Plan. Soc Sci Med 172, 10-18.

33. Fitzgerald N \& Spaccarotella K (2009) Barriers to a healthy lifestyle: from individuals to public policy - an ecological perspective. $J$ Ext 47, issue 1, 1FEA3.

34. National Aboriginal Community Controlled Health Organisation (2003) National Strategic Framework for Aboriginal and Torres Strait Islander Health. Canberra, ACT: NACCHO.

35. Nelson A, Abbott R \& Macdonald D (2010) Indigenous Austalians and physical activity: using a social-ecological model to review the literature. Health Educ Res 25, 498-509.

36. Rowley K, Doyle J, Johnston L et al. (2015) Strengths and limitations of a tool for monitoring and evaluating First Peoples' health promotion from an ecological perspective. BMC Public Health 15, 1215.

37. Islam S \& Fitzgerald L (2016) Indigenous obesity in the news: a media analysis of news representation of obesity in Australia's Indigenous population. BMC Obes $\mathbf{3}, 30$. 
38. Bowen G (2009) Document analysis as a qualitative research method. Qual Res J 9, 27-40.

39. Markwick A, Ansari Z, Sullivan M et al. (2014) Inequalities in the social determinants of health of Aboriginal and Torres Strait Islander People: a cross-sectional population-based study in the Australian state of Victoria. Int J Equity Health 13, 19.

40. Council of Australian Governments (2009) National Strategy for Food Security in Remote Indigenous Communities. http://webarchive.nla.gov.au/gov/20130329094202/http:// www.coag.gov.au/node/92 (accessed August 2016).

41. Bonfiglioli C, Smith B, King L et al. (2007) Choice and voice: obesity debates in television news. Med J Aust 187, 442-445.

42. Bastian A (2011) Representations of childhood obesity in Australian newsprint media and academic literature. Aust $N$ Z J Public Health 35, 135-139.

43. Australian Government Department of Health (2017) Social and Cultural Determinants of Indigenous Health. https:// consultations.health.gov.au/indigenous-health/determinants/ (accessed May 2017).

44. Boelsen-Robinson T, Peeters A, Beauchamp A et al. (2015) A systematic review of the effectiveness of whole-ofcommunity interventions by socioeconomic position. Obes Rev 19, 806-816.

45. Lee V (2017) Political determinants and Aboriginal and Torres Strait Islander women: don't leave your integrity at the political gate. J Public Health Policy (Epublication ahead of print version).
46. Hunt J (2013) Engaging with Indigenous Australia exploring the conditions for effective relationships with Aboriginal and Torres Strait Islander communities. Produced for the Closing the Gap Clearinghouse. http://www.aihw. gov.au/uploadedFiles/ClosingTheGap/Content/Publications/ 2013/ctgc-ip5.pdf (accessed August 2017).

47. Yeatman H (2009) Action or inaction? Food and nutrition in Australian local governments. Public Health Nutr 12, 1399-1407.

48. Yeatman HR (2003) Food and nutrition policy at the local level: key factors that influence the policy development process. Crit Public Health 13, 125-138.

49. Victorian Health Promotion Foundation (2011) Food for All Program 2005-10: Evaluation Report. Carlton, VIC: VicHealth.

50. Murray M, Bonnell E, Thorpe $S$ et al. (2014) Sharing the tracks to good tucker: identifying the benefits and challenges of implementing community food programs for Aboriginal communities in Victoria. Aust J Prim Health 20, 373-378.

51. Clavier C \& de Leeuw E (2013) Health Promotion and the Policy Process. Melbourne, VIC: Oxford University Press.

52. Department of Health and Human Services (2013) Healthy Together Victoria Frequently Asked Questions. https://www2.health.vic.gov.au/Api/downloadmedia/\%7B9 C4CBAFB-B9B1-424A-A029-B3F7EDF3D28C\%7D (accessed August 2017).

53. Victoria State Government (2016) Department of Health and Human Services annual report 2015-16. http://www. dhhs.vic.gov.au/publications/department-health-and-humanservices-annual-report-2015-2016 (accessed May 2017). 